\title{
Treatment of short bowel syndrome in children. Value of the Intestinal Rehabilitation Program
}

\author{
Uenis Tannuri ${ }^{1 *}$, Fabio de Barros ${ }^{2}$, Ana Cristina Aoun Tannuri ${ }^{3}$ \\ ${ }^{1}$ Full Professor, Department of Pediatric Surgery and Liver Transplant, Faculdade de Medicina, Universidade de São Paulo (FMUSP). Head of the Service of Pediatric Surgery and Liver Transplant at Instituto da Criança, \\ Hospital das Clínicas, and of the Pediatric Surgery Research Laboratory, FMUSP. Head of the Laboratory of Pediatric Surgery at Hospital das Clínicas, FMUSP, São Paulo, SP, Brazil \\ 2Physician, Service of Pediatric Surgery, Instituto da Criança, Hospital das Clínicas, FMUSP, São Paulo, SP, Brazil \\ ${ }^{3}$ Associate Professor, Department of Surgical Technique and Experimental Surgery, FMUSP. Physician, Service of Pediatric Surgery, Instituto da Criança, Hospital das Clínicas, and the Pediatric Surgery Research \\ Laboratory (LIM-30), FMUSP, São Paulo, SP, Brazil
}

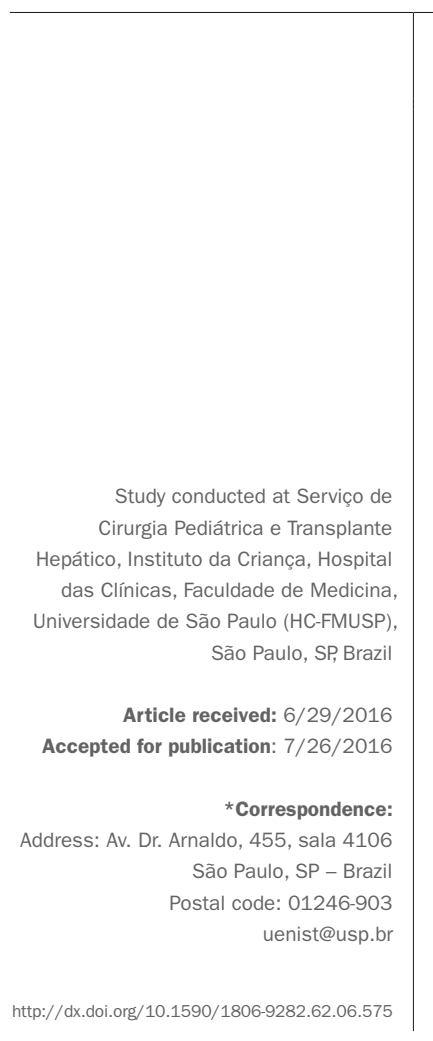

\section{SUMMARY}

The main cause of acute intestinal failure is short bowel syndrome, generally as a result of resection of extensive segments of small intestine. As a result, the main symptoms are watery diarrhea, malabsorption syndrome, chronic malnutrition, and death, if the patient is not properly treated. If the length of the remaining intestine is greater than $30 \mathrm{~cm}$, complete adaptation is possible and the patient may not require parenteral nutrition. The currently recommended treatment includes the use of prolonged parenteral nutrition and enteral nutrition, always aimed at constant weight gain, in conjunction with surgeries aimed at elongating the dilated bowel. This set of procedures constitutes what is called an Intestinal Rehabilitation Program. This therapy was used in 16 children in periods ranging from 8 months to 7.5 years, with survival in $75 \%$ of the cases. Finally, the last resort to be used in children with complete resection of the small bow$\mathrm{el}$ is an intestinal transplant. However, to date there is no record of a Brazilian child that has survived this procedure, despite it being attempted in seven patients. We conclude that the results of the intestinal rehabilitation program are encouraging for the continuation of this type of treatment and stimulate the creation of the program in other pediatric care institutions.

Keywords: short bowel syndrome, child, intestinal failure, prolonged parenteral nutrition, intestinal rehabilitation.

\section{INTRODUCTION}

Acute changes in intestinal function may be related to various clinical or surgical diseases in children. However, short bowel syndrome is the most important and serious cause of acute intestinal failure. The designation "short" stems from the fact that the disease is acquired after a surgical procedure, where resection of extensive segments of the intestine is necessary due to non-viable intestinal structures. This results in a clinical condition, characterized by fast intestinal transit leading to diarrhea and nutrient malabsorption. It may also be caused by partial resections of the intestine if the remaining portions function poorly. The clinical manifestations depend on the length of the remaining portions of the jejunum and ileum, the presence of an intestinal bypass, the presence or absence of the ileocecal valve, the remaining length of the colon and the persistence of intestinal disease. The most fre- quent causes in newborns are necrotizing enteritis, midgut volvulus and other congenital malformations such as intestinal atresia, intestinal aganglionosis, and gastroschisis. In older children, the most important causes are intestinal volvulus and resections of extensive intestinal segments in repeated abdominal surgeries, indicated by the presence and complications caused by intestinal adhesions. Other important causes of intestinal function failure with difficult clinical treatment refer to intestinal neuronal dysplasia and all other forms of chronic intestinal pseudo-obstruction. ${ }^{1}$

This review will discuss the current aspects of short bowel syndrome (SBS). In 2004, a Dutch national committee composed of pediatricians, gastroenterologists and pediatric surgeons reached a consensus for the definition of SBS: resection of more than $70 \%$ of the small intestine and/or need for parenteral nutrition for more than 42 
days after intestinal resection and/or remaining length of the small intestine from the angle of Treitz of less than $50 \mathrm{~cm}$ for premature infants, less than $75 \mathrm{~cm}$ for term newborns and less than $100 \mathrm{~cm}$ for a 1 year old child. ${ }^{2}$

Until the beginning of the 1970s, children with SBS died early as a result of malnutrition that occurred quickly due to the lack of effective nutritional treatment. The introduction of prolonged parenteral nutrition by then, together with appropriate dietary measures, has substantially changed the prognosis of children subjected to major small intestine resections. More recently, hospital programs with groups of professionals specifically designated and trained for the treatment of these patients have been responsible for the recovery of a large number of patients. This prevents the last surgical resort, that is, intestinal transplant, which may be indicated in children with complete resection of the small intestine or those in which the vascular access routes for intravenous administration of nutrients have been exhausted.

\section{INCIDENCE, ETIOLOGY, AND PATHOLOGY}

In the Brazilian literature there are no publications on the prevalence of SBS. According to international publications, it is estimated at around 3 to 5 cases per 100,000 births per year. However, it is known that the occurrence has increased in recent years as a result of improved services for newborns in neonatal intensive care units.

In our country, most SBS cases occur in the neonatal period, as a result of vascular changes to the intestine during intrauterine development. The second cause consists of acquired intestinal problems requiring resection of the large intestine, in which case necrotizing enteritis and intestinal volvulus are the most important causes, as quoted previously. ${ }^{3}$

Soon after intestinal resection, the main digestive symptom is diarrhea, due to poor absorption of nutrients and water. However, the intensity of symptoms will depend on the absorption capacity of the remaining intestine. Adaptive phenomena that are intended to increase the absorption of fluids and nutrients occur, such as: dilation and elongation of the bowel loops, thickening of the wall, hyperplasia of the mucosal villi, increased depth of crypts, acceleration of proliferation rates of enterocytes, and hyperplasia of the fibers in the muscular layer. This adaptation phase can last from 1 to 2 years, during which intestinal absorption is inadequate, therefore requiring parenteral nutrition.

The ability to absorb water and nutrients depends on the length of the small intestine, but also on the presence of the colon and the ileocecal valve. In general, resection of the jejunum, even if of extensive segments, only causes a transitory reduction in absorption of nutrients, due to the large absorptive capacity of the ileum, the enterohepatic circulation of bile salts and of vitamin B12. Generally, the resection of large sections of the ileum may cause consequences that are more harmful to intestinal function. After a meal with hypertonic content, there is usually a large supply of water into the lumen of the first jejunal loops, in order to make the content isotonic and allow absorption of nutrients. After resection of the ileum, the jejunal content comes directly to the colon, which has to increase its absorptive capacity. Another consequence of resection of the ileum is inadequate absorption of vitamin B12 and bile acids, which causes diarrhea if they reach the lumen of the colon. Also, the loss of the ileum causes depletion of the "pool" of bile salts, which in turn causes a reduction in the absorption of fat and fat-soluble vitamins. Under normal conditions, hydrolyzed bile acids bind with calcium to form calcium stearate and prevent the absorption of this ion, which also binds with oxalates, preventing their absorption. Thus, in children with short bowel syndrome, the reduced "pool" of bile acids will be responsible for increased absorption of oxalates, with consequent oxaluria and formation of urinary calculi containing oxalates. Similarly, due to the reduction of calcium in the intestinal lumen, promoted by the increased absorption, unconjugated bilirubin remains in solution, increasing its content in the enterohepatic circulation, changing the constitution of the bile and leading to a tendency for the formation of gallstones.

Adaptation phenomena occurring after resection of extensive portions of the intestine are responsible for normalization of the digestive function, with oral nutrition in normal conditions in approximately $90 \%$ of children with short bowel syndrome. These phenomena consist of increased blood flow to the remaining intestine, intestinal growth and dilation, increased absorption surface, growth of the intestinal villi and of the depth of the crypts. The pathophysiology of these adaptive mechanisms is not well understood, although it is universal knowledge that the presence of nutrients in the intestinal lumen with increased digestive secretions is the most important stimulus for intestinal growth.

The presence of nutrients in the intestinal lumen stimulates the secretion of trophic polypeptides and other mediators such as gastrin, enteroglucagon, and enteroglucagon precursors such as glucagon-like peptide-2 (GLP-2). Also, recent research has valued growth hormone both alone and in combination with epidermal growth factor or insulin growth factor-1 (IGF-1). Finally, there is evidence that glutamine is an important amino acid for intestinal 
tropism and growth, given that, according to investigations, the administration of growth hormone promotes increased uptake of glutamine after intestinal resection. ${ }^{4}$

\section{TREATMENT}

The clinical evolution of patients with SBS is divided into three phases: the initial acute phase following the surgical procedure is characterized by intense diarrhea and consequential electrolyte disturbances, gastric acid hypersecretion and gastrinemia, generally lasting around a month. In this period, electrolytes must be replaced, and acid-base balance disturbances must be corrected. Next is the adaptation phase, which can last from a few months to a year. In this period, parenteral nutrition and enteral nutrition with adequate diets are administered, diarrhea is less intense and the nutritional state tends to stabilize, as long as the patient is properly treated. Eventually, there comes the maintenance phase, in which, even though poor absorption is still present, it often becomes possible to interrupt parenteral nutrition and keep the patient on exclusive oral nutrition. Gains in weight and height will depend on the absorptive capacity of the remaining intestine. It is known that the adaptation of the remaining small intestine always depends on adequate maintenance of the nutritional state, with growth and somatic development, even at the expense of parenteral nutrition and enteral nutrition with artificial diets. In general, when the length of the remaining small intestine is greater than $30 \mathrm{~cm}$, the patient can be adapted in intervals of up to 1 year and be free of parenteral nutrition with exclusive oral nutrition.

From a surgical point of view, a child with SBS may depend on the following procedures:

1. Obtaining venous access for prolonged parenteral nutrition.

2. Surgical procedures to lengthen the remaining intestine and improve its absorptive ability.

3. Being treated by a group of professionals trained in intestinal rehabilitation programs.

\section{Venous access}

The most important aspect in patients with SBS refers to how both the pediatrician and the surgeon will obtain and maintain venous access for the administration of nutrients for as long as possible. Whenever there is no possibility of recovering the intestine, the survival time of the patient depends on the durability of the central catheters.

The placement of a central venous catheter should always be carried out in the operating room under gen- eral anesthesia. The catheters must be put in place by puncturing the central veins, with venous dissections as the second option. As such, the veins of the superior vena cava should preferably be punctured, namely the internal jugular and subclavian veins. The choice between these depends on the experience of the surgeon, remembering that puncture of the subclavian vein is associated with an increased risk of pneumothorax or hemothorax. The femoral veins, although associated with absence of pneumothorax or hemothorax and less puncture accidents, are left as the second choice due to greater difficulties in the handling of dressings. After the vein is punctured, the catheter is introduced using a classic and widely used technique called Seldinger, in which the catheter is threaded over a guide wire.

In young children or in the presence of blood dyscrasias, one may opt for venous dissection. The first choice for access to the central veins is based on tributary veins of the superior vena cava system: the basilic or axillary veins in the axilla and the internal or external jugular veins or facial vein in the neck. In older children or teenagers, the cephalic vein in the deltopectoral sulcus may present good caliber and provide another option for venous access. Tributary veins of the inferior cava system may be used when the veins referred to above are not available due to previous dissections or thrombosis of the superior vena cava. In these cases, the saphenous arch or inferior deep epigastric veins are the most used. The choice of the inferior vena cava system is valid and justified by the low rate of complications and also by the fact that thrombosis of iliac veins or inferior cava are often asymptomatic, unlike thrombosis of superior vena cava.

Regardless which vein is used, radiographic control of the correct position of the catheter is essential to contrast via radiography or radioscopy carried out in the operating room before closing the incision of the phlebotomy. The tip of the catheter should be positioned at the entrance to the right atrium or approximately $1 \mathrm{~cm}$ inside it. Incorrect positions must be promptly corrected, as they may lead to venous thrombosis.

The catheter should be externalized through a counter-opening, at a distant location from the entry point of the vein after traveling through a subcutaneous tunnel. The dressings must be meticulously changed every 2 or 3 days or at any time if there is an extravasation of the solution, using antiseptic solutions.

Usually, Hickman or Broviac silicone semi-implantable catheters or fully implantable catheters (port-a-cath) are used. Preference should be given to catheters made of 
silicone instead of polyurethane or polyvinyl because they are less thrombogenic.

Catheters are responsible for the occurrence of repeated infections and thrombosis of the superior and inferior vena cava, which are the most frequent long-term complications in children with SBS. The repeated exchange of catheters may lead to exhaustion of all the conventional access routes, requiring alternative methods to obtain access to central vein. Therefore, dissection of the azygos vein or its branches (intercostal veins) has been reported and standardized in our service through right thoracotomy, with placement of a port-a-cath and fixation of the chamber on the anterior surface of the chest. Another option is to make a purse-string suture in the atrial appendage and insertion of the catheter directly into the right atrium. Furthermore, transhepatic punctures have been described for access to the suprahepatic veins that drain directly into the inferior vena cava. ${ }^{5}$

\section{Prolonged parenteral nutrition and enteral nutrition}

Prolonged parenteral nutrition should be indicated ear$l y$, in the first few days after surgery, shortly after hemodynamic stabilization of the child and correction of electrolyte disorders. This should at first be undertaken in hospital environment; and later, during the maintenance phase, it may be performed in the patient's home. Another possibility is the administration of nutrients in an outpatient hospital regime for daily periods of 6 to 8 hours, in addition to oral nutrition.

At the patient's home, the solutions can be administered during the day or night. The advantage of the first option is its greater safety, which makes the use of infusion pumps expendable. If the administration is done at night, the child may have normal activity during the day; however, the use of an infusion pump with an alarm system is essential in case of air entrapped in the infusion system. Some children do not tolerate rapid administration of large volumes of hypertonic solutions and require continual infusions over 24 hours daily.

The most serious and frequent complication for children with SBS on a parenteral nutrition regimen is systemic infection, stemmed from the presence of a central venous catheter, as previously mentioned. It is important to investigate any noncompliance with the rules of the protocol for handling the catheter and solutions. Failure to find a specific source of infection and the persistence of fever results in intravenous administration of broad-spectrum antibiotics. On the other hand, the situation is potentially serious when the blood culture reveals Staphylococcus aureus or S. epidermidis. Specific antibiotics for a three-week period are recommended in these cases. Fungal infections must be treated with medication and removal of the catheter. Last, catheter obstruction caused by blood clots is a frequent problem and often involves exchange of the catheter, using the same vein.

The solutions to be administered containing all of the nutrients mixed into one bottle are specified in Table 1. The mixture contains a caloric source in the form of glucose and lipid emulsion, a solution of crystalline amino acids, electrolytes, vitamins, and trace elements.

\begin{tabular}{|c|c|c|}
\hline Component & Amount & $\begin{array}{l}\text { Final concentration } \\
\text { (per liter) }\end{array}$ \\
\hline Glucose $50 \%$ & $250 \mathrm{~mL}$ & $125 \mathrm{~g}$ of glucose \\
\hline Amino acids $10 \%$ & $200 \mathrm{~mL}$ & $20 \mathrm{~g}$ of amino acids \\
\hline Sodium acetate $10 \%$ & $20 \mathrm{~mL}$ & $20 \mathrm{mEq}$ of sodium \\
\hline Magnesium sulphate $10 \%$ & $10 \mathrm{~mL}$ & $8 \mathrm{mEq}$ of magnesium \\
\hline Sodium glycerophosphate & $8 \mathrm{~mL}$ & $1 \mathrm{mmol}$ of phosphate \\
\hline $1.0 \mathrm{mmol} / \mathrm{mL}$ & & $16 \mathrm{mEq}$ of sodium \\
\hline Potassium chloride $19.1 \%$ & $10 \mathrm{~mL}$ & $25 \mathrm{mEq}$ of potassium \\
\hline Calcium gluconate $10 \%$ & $20 \mathrm{~mL}$ & $9 \mathrm{mEq}$ of calcium \\
\hline Trezevit A & $5 \mathrm{~mL}$ & (see Table 2) \\
\hline Trezevit B & $5 \mathrm{~mL}$ & (see Table 3) \\
\hline Mixture of trace elements & $1 \mathrm{~mL}$ & (see Table 4) \\
\hline Lipid emulsion $20 \%$ & $100 \mathrm{~mL}$ & $20 \mathrm{~g}$ of lipids \\
\hline Distilled water q.s.p. & $1000 \mathrm{~mL}$ & \\
\hline Osmolarity (mOm/L) & & 900 to 1000 \\
\hline $\mathrm{N} /$ cal ratio & & $1 / 200$ \\
\hline
\end{tabular}

\section{TABLE 2 Composition of vitamin mixture.}

\begin{tabular}{lll} 
Trezevit A & Adult & Pediatric \\
\hline Vitamin A (retinyl palmitate) & $3300 \mathrm{IU}$ & $2300 \mathrm{IU}$ \\
\hline Vitamin D3 (cholecalciferol) & $200 \mathrm{IU}$ & $400 \mathrm{IU}$ \\
\hline Vitamin E (alpha tocopherol acetate) & $10 \mathrm{IU}$ & $7 \mathrm{IU}$ \\
\hline Vitamin K1 (phytomenadione) & $150 \mathrm{mcg}$ & $200 \mathrm{mcg}$ \\
\hline Vitamin B1 (thiamine hydrochloride) & $6 \mathrm{mg}$ & $1.2 \mathrm{mg}$ \\
\hline Vitamin B2 (riboflavin sodium phosphate) & $3.6 \mathrm{mg}$ & $1.4 \mathrm{mg}$ \\
\hline Vitamin B3 (nicotinamide) & $40 \mathrm{mg}$ & $17 \mathrm{mg}$ \\
\hline Vitamin B5 (dexpanthenol) & $15 \mathrm{mg}$ & $5 \mathrm{mg}$ \\
\hline Vitamin B6 (pyridoxine hydrochloride) & $6 \mathrm{mg}$ & $1 \mathrm{mg}$ \\
\hline Vitamin C (ascorbic acid) & $200 \mathrm{mg}$ & $80 \mathrm{mg}$ \\
\hline Water for injection q.s.p. & $5 \mathrm{~mL}$ & $5 \mathrm{~mL}$ \\
\hline
\end{tabular}


TABLE 3 Composition of the second vitamin mixture.

\begin{tabular}{lll} 
Trezevit B & Adult & Pediatric \\
\hline Vitamin B7 (biotin) & $60 \mathrm{mcg}$ & $20 \mathrm{mcg}$ \\
\hline Vitamin B9 (folic acid) & $600 \mathrm{mcg}$ & $140 \mathrm{mcg}$ \\
\hline Vitamin B12 (cyanocobalamin) & $5 \mathrm{mcg}$ & $1 \mathrm{mcg}$ \\
\hline Water for injection q.s.p. & $5 \mathrm{~mL}$ & $5 \mathrm{~mL}$ \\
\hline
\end{tabular}

TABLE 4 Composition of the mixture of trace elements.

\begin{tabular}{lll} 
Component & Amount $(\mathrm{g})$ & Concentration $(\mathbf{m c g} / \mathbf{m L})$ \\
\hline $\mathrm{ZnSO}_{4} \cdot 7 \mathrm{H}_{2} \mathrm{O}$ & 1.9 & zinc-400 \\
\hline $\mathrm{CuSO}_{4} \cdot 6 \mathrm{H}_{2} \mathrm{O}$ & 0.9 & copper-200 \\
\hline $\mathrm{NaF}$ & 0.22 & fluorine-10 \\
\hline $\mathrm{NaI}$ & 0.069 & iodine-59 \\
\hline $\mathrm{MnSO}_{4} \cdot \mathrm{H}_{2} \mathrm{O}$ & 0.62 & manganese-200 \\
\hline
\end{tabular}

The concomitant supply of nutrients orally or through a nasogastric tube is always recommended. Delivering nutrients directly into the stomach is particularly advantageous when using chemically defined diets with a disagreeable flavor, which are not very acceptable to children when orally ingested. On the other hand, the catheter enables diets to be infused continuously, which allows better absorption.

\section{Diets}

The introduction of diets should be undertaken in the initial phase, when there is hemodynamic and electrolyte stabilization and the child has overcome the paralytic ileus period, with the intestinal transit reestablished. The introduction should be made with elemental diets, with some degree of prior digestion of nutrients. In general, the diet should contain carbohydrates, fats and proteins in the ratio of 5:3:2, electrolytes, vitamins, and trace elements. After full dilution, the diet's osmolarity should be no higher than the plasma's (300 $\mathrm{mOsm} / \mathrm{L}$ ). Remember that children with SBS tolerate any type of hyperosmolar diet poorly, even when introduced into the stomach. The different types of diets are presented below:

1. Natural diets. In the preparation, natural elements without any prior manipulation are used: full fat or skimmed cow's milk, soy, meat fiber, meat broth, egg, butter, which may be mixed with certain commercial formulas (Isolac ${ }^{\circledR}$, Karo $^{\circledR}$, Nidex $^{\circledR}$, Casec $^{\circledR}$ etc). The main advantage of these diets is easy handling, with preparation possible in the child's own home. The biggest disadvantage is that they usually require a gastrointestinal tract whose length is not greatly compromised, because they are not digested in advance and must be administered via the stomach.
2. Dairy diets. These are widely used. It must be remembered that human milk, due to its protective properties and stimulation of digestive maturation, should be preferred for newborns in any clinical situation, whenever possible. This begins with small doses and gradual increases, as an exclusive food or associated with other types of milk.

3. Dietary supplements. These are generally synthetic preparations, used only to enrich existing formulas. They may be simple (TCM ${ }^{\circledast}, \mathrm{Casec}^{\circledR}$ etc) or compounds, in which several nutrients are mixed (Meritene ${ }^{\circledR}$, Sustacal $^{\circledR}$ etc).

4. Elemental and semi-elemental diets containing previously hydrolyzed proteins and carbohydrates. The Brazilian market offers various types of diets, most commonly the Alfaré ${ }^{\circledast}$, Pregestimil ${ }^{\circledast}$, and Neocate ${ }^{\circledast}$ brands. They should initially be offered in diluted form and in small quantities, and progressively increased in volume and concentration, depending on the acceptance and tolerance, which are basically represented by the emergence or worsening of diarrhea and dehydration.

5. Modular diets. These are widely used in practice, particularly in hospitals and in patients with few resources. The natural and low cost nutrients are added gradually one at a time, in variables lengths of time, depending on adaptation to the nutrient introduced beforehand. These diets, which are easy to prepare and easily available, contain: carbohydrates (cream of rice, potato starch or glucose), fat (medium chain triglycerides, babassu or corn oil), protein (chicken fiber or crystalline amino acids), mineral salts, vitamins $\mathrm{A}, \mathrm{D}, \mathrm{E}, \mathrm{K}, \mathrm{B} 12$, and biotin.

In the first week runs, a mixture of $3 \%$ cream of rice, $5 \%$ glucose, and a small portion of kitchen salt are administered. If there is good acceptance, without diarrhea, in the following week $10 \%$ chicken broth is added, followed by $20 \%$ and, at the end of the week, $1 \%$ medium chain triglycerides are added. In the third week, $10 \%$ chicken fiber is added with a few drops of lemon with the objective of supplying vitamins, especially vitamin C.

In the fourth week, fiber concentration is increased to $20 \%$ and medium chain triglycerides to 2 and $3 \%$, progressively. In this phase, minerals begin to be supplied as a mixture of sodium chloride, potassium chloride, calcium gluconate, potassium phosphate, and magnesium sulfate or through the addition of leaf vegetable broth.

In the fifth week, pasta or boiled potatoes can be added to the soups, starting with $50 \mathrm{~g}$ a day up to the limit of $200 \mathrm{~g}$. Medium chain triglycerides may be re- 
placed by corn oil at an equal percentage. Finally, cooked egg yolk is introduced, half at the beginning and then the entire unit. This diet is maintained for 2 to 3 months and, if there is no diarrhea, the transition to soy milk can be undertaken.

It is important to note that during the administration of one of the enteral diet types, weight loss, dehydration, and loss of electrolytes occur in most cases, which always require the administration of parenteral nutrition as concomitant support.

As stressed above, the introduction of enteral diets or oral diets is slow and subject to regressions and/or suspensions, depending on the child's response. Only after stool volume and consistency are clearly stable other less digested and more natural foods can be introduced. In the maintenance and stabilization phases, the gradual introduction of the diets is also an excellent clinical assessment test in relation to the adaptation of the intestine. Laboratory assessments with complicated intestinal absorption tests have little value and meaning from a therapeutic point of view. Also, the interpretation of a particular test is of little practical applicability. Sometimes, the attempted introduction of a certain diet, followed by proper and reasonable assessment of the clinical response of the child, has greater value.

Certain medications can complement the clinical treatment. Thus, the gastric hypochlorhydria in the early stage can be reversed with the administration of $\mathrm{H} 2$ receptor antagonists or proton-pump inhibitors. Watery diarrhea and fast intestinal transit can be controlled with the administration of opioids or loperamide. Other drugs cited in scientific investigations are: octeotride acetate, an analogue of somatostatin that inhibits gastrointestinal secretions, and whose current use is limited due to the high cost; cholestyramine, which by binding to bile salts can have a beneficial effects in cases of diarrhea induced by the high content of bile salts in the colon; and ursodeoxycholic acid, which inhibits the uptake of bile acid metabolites that cause harmful effects to the liver parenchyma. In children with resection of the ileum, oxaluria levels should be monitored and, if high, dietary restriction of oxalate intake should be recommended, with calcium supplementation. Metabolic bone disease can be prevented with the administration of calcium, vitamin $\mathrm{D}$ and other fat-soluble vitamins, and vitamin B12.

\section{Surgical procedures to lengthen the remaining intestine and im-} prove its absorptive ability

In general, clinical treatment must be maintained for a period of one year. Cases in which keeping the child ex- clusively on enteral nutrition during this period is not possible are labeled as SBS refractory to clinical treatment, making the child a candidate for surgical treatment. Classically, most children with more than $20 \mathrm{~cm}$ of small intestine and ileocecal valve, or over $40 \mathrm{~cm}$ without the valve, have a high chance of survival without parenteral nutrition and without the need for surgical treatment.

Surgical treatment may be indicated for those children who cannot achieve functional adaptation of the residual intestine or those that present any bowel obstruction or major dilations during the evolution of treatment. Below, we describe the surgical techniques proposed by different authors with the intention of improving the absorptive capacity of the intestine. They can be used alone or combined with each other. In practice, these surgical techniques are not responsible for increasing the absorptive surface of the short intestine and therefore do not enable withdrawal from parenteral nutrition without the occurrence of spontaneous adaptation of the remaining intestine, with prolonged parenteral nutrition.

\section{Valves}

These have the objective of impeding the transit and preventing the reflux of bacteria from the colon. The valves partially obstruct the transit of small intestine, causing progressive dilatation of the intestine, muscular hypertrophy, and proliferation of the crypt cells.

\section{Enteroplasty}

This involves surgical procedures to reduce the dilated loops, with the goal of decreasing stasis and bacterial hyper-colonization, as well as eventual bacterial translocation.

\section{Intestinal lengthening}

The first technique was described by Bianchi. It consists of dividing the dilated intestine in two parallel intestinal segments, with the use of a stapler, dividing the irrigation equally between both segments. The separated segments are anastomosed in continuity, doubling the length of the intestine. ${ }^{6}$

Recently, serial transverse enteroplasty (STEP) has been introduced as a new option for surgical lengthening of the intestine in SBS. STEP involves sequential linear stapling of the dilated small intestine in alternate directions perpendicular to the longitudinal axis of the intestine. As such, all the applications of the stapler are performed in parallel with the direction of the mesenteric flow, so that the intestinal blood supply is not placed at risk. There are reports (in humans and experimental models) suggesting that STEP improves the ability of the in- 
testine to absorb macronutrients and reduces occurrence of bacterial translocation, enabling the withdrawal of parenteral nutrition. However, the greatest limitation of the clinical studies is the absence of controls groups. ${ }^{7}$

\section{The Intestinal Rehabilitation Program at Instituto da Criança (Children's Institute), HC-FMUSP}

Experience in the treatment of children with SBS at our institution began in the late 1980s after the introduction and standardization of parenteral nutrition as a routine and effective method. In 1982, we undertook the first home-based, prolonged parenteral nutrition in the country. ${ }^{8}$ In the first study period, 19 children with resection of more than $75 \%$ of the intestinal length were initially treated at the hospital and then in their own homes. The total periods of nutritional therapy ranged from 4 months to 4.5 years, and the children remained on parenteral nutrition at home for periods ranging from 1 week to 4 years. Weight gain, growth, and satisfactory development were found in all cases, and seven children (36.8\%) survived free from parenteral nutrition. ${ }^{3}$

By the end of 2010, the introduction of certain changes and technical standardization produced encouraging results. These modifications, in conjunction with prolonged treatment based on enteral and parenteral nutrition aimed always at constant weight gain for the patient, constitute what is known as an Intestinal Rehabilitation Program. ${ }^{9}$ These standardizations include the following:

1. Formation of a team of physicians, nurses, and nutritionists for the treatment of patients, with physicians with good experience and surgical skill in the placement and replacement of central venous catheters. Obtainment of a central venous access route is vital and indispensable to the continuity of treatment.

2. Constant use of parenteral nutrition and introduction of enteral nutrition, as early as possible, whenever there is intestinal transit. After the patient's stabilization period, usually after 4 to 6 months, parenteral nutrition can be administered in cyclic form, with the infusion of nutrients interrupted for periods of 6 to 8 hours.

3. Rigorous caution with the central catheters, always bearing in mind that all therapeutic resources should be used before replacing the catheter, in case of infection or occlusion of the lumen due to blood coagulation.

4. Introduction of a new technique for prevention of catheter-related infection, which consists of infusion of ethanol locks. A daily injection of 2 to $3 \mathrm{~mL}$ of $70 \%$ ethanol solution is given, enough to fill the lumen of the catheter, which is maintained for the period during which the administration of the nutrient solution is interrupted, generally from 2 to 6 hours. After this period, the ethanol is aspirated and the catheter is treated with saline for use. ${ }^{10}$

5. Use of lipid emulsions containing fish oil (rich in omega-3) for the prevention of liver disease caused by prolonged parenteral nutrition. Studies have shown that lipid emulsions containing omega- 3 promote improvement of the bile flow, reduce the levels of circulating phytosterols, regulate the levels of inflammatory prostaglandins responsible for reduction of the bile flow, and act directly on the hepatocyte membrane composition, facilitating the transport of bile. ${ }^{11-13}$

6. Indication of intestinal lengthening surgeries based on the serial transverse enteroplasty technique.

To date (May 2016), 16 children with SBS have been treated according to the protocol described above. All of the children had a small intestine with less than $30 \mathrm{~cm}$ in length, and in four of them there was complete resection of the small intestine. The conditions responsible for the short intestine were: gastroschisis (five patients), midgut volvulus (four patients), necrotizing enteritis (three patients), multiple intestinal atresias (three patients), and giant teratoma at the root of the mesentery with involvement of the superior mesenteric artery (one patient). Treatment periods ranged from 8 months to 7.5 years. Eight intestinal lengthening surgeries (STEP) were performed in five children.

As a result, four children remain hospitalized, two children are being treated at home, three receive parenteral nutrition in an outpatient regimen and four children died as a result of septicemia ( $75 \%$ survival) (Figure 1). Finally, three children were able to withdraw from parenteral nutrition and currently maintain exclusive oral nutrition. The comparison with the group of children treated in the first period of the study shows statistically significant results ( $\mathrm{p}=0.03$, Fisher's test).

\section{SMALl INTESTINE TRANSPLANTATION}

Intestine transplantation is the final surgical option for the treatment of SBS. It is indicated in the following situations: ${ }^{14,15}$

- Patients with total resection of the small intestine.

- Liver disease secondary to prolonged parenteral nutrition, characterized by bilirubin levels exceeding $3 \mathrm{mg} / \mathrm{dL}$, presence of splenomegaly, thrombocytopenia, esopha- 

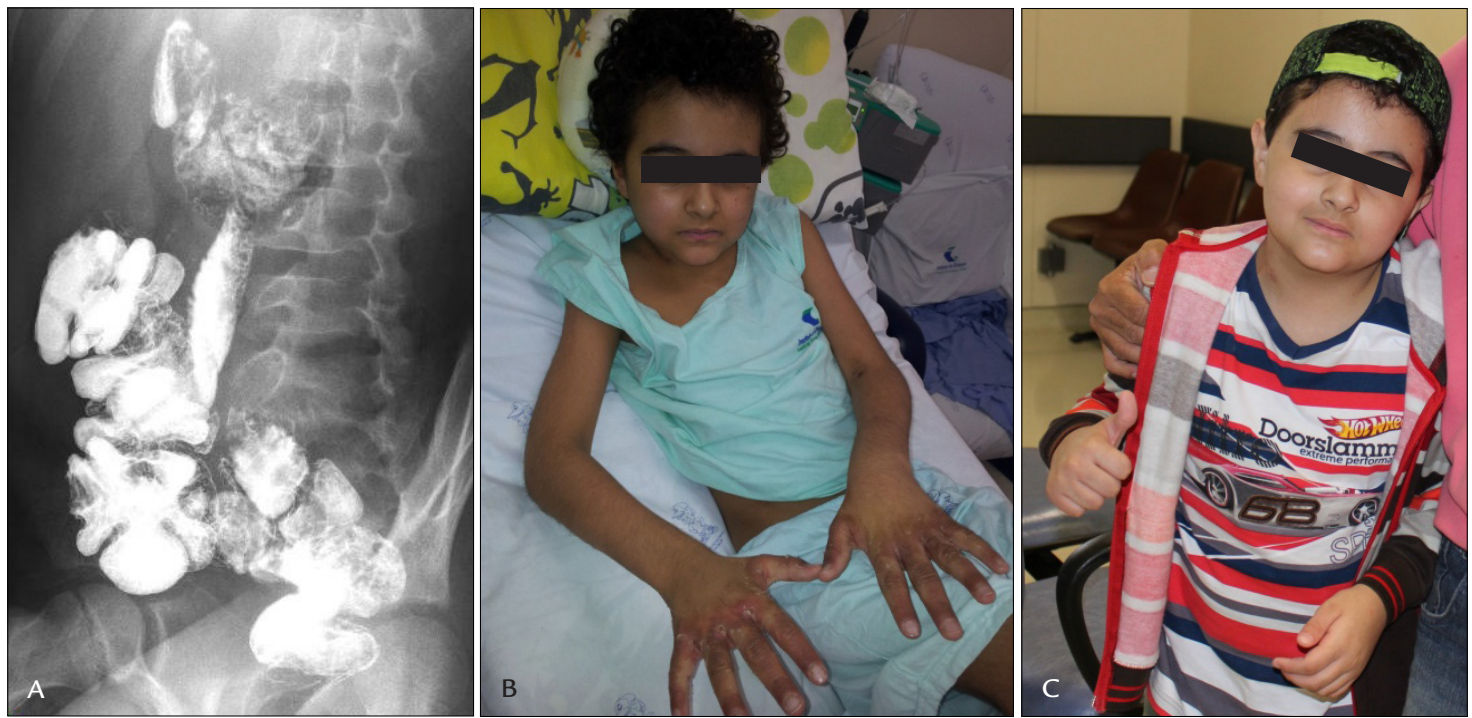

FIGURE 1 Child aged 10 years with short bowel syndrome. Presented acute abdomen at the age of 4 years, with necrosis of the small intestine and colon. Subjected to massive bowel resection, leaving only the duodenum and left colon (A - contrast radiography). The patient was admitted with a weight of $13.5 \mathrm{~kg}$ and skin lesions suggestive of zinc deficiency (B). After 5 years of exclusive parenteral nutrition (C), clinical status became excellent, without any signs of nutritional deficiency and a final weight of $34 \mathrm{~kg}$. It should be stressed that the liver function is normal, without changes to the hepatocellular or canalicular enzymes. Despite considering the hypothesis of a small intestine transplant, it should be remembered that the patient survived with excellent results and good quality of life compared to other children treated with intestinal transplantation.

geal varices, coagulopathy, bleeding stomas, liver fibrosis or cirrhosis.

- Presence of thrombosis in the main central venous access points, with more than two thromboses in the subclavian, femoral or jugular veins.

Absolute contraindications for intestinal transplant include: progressive neurological dysfunction, active sepsis, intractable disease affecting extra-intestinal organs, malignancy, and serious psychosocial problems. Relative contraindications are: patient hospitalized in intensive care, immunodeficiency, drug addictions, loss of conventional venous access, benign neoplasm of doubtful prognosis, and children weighing less than $10 \mathrm{~kg}$.

Types of intestinal grafts: depending on the needs of the patient with intestinal failure, the grafts can be transplanted as small intestine alone, or a compound graft that may include the liver, duodenum, pancreas, and/or stomach. Compound grafts are designated as liver/intestine or multivisceral grafts. Obtaining various forms of grafts is based on preservation of the blood flow through the celiac artery and superior mesenteric artery and the venous drainage through the superior mesenteric vein in the isolated intestinal graft, or the hepatic veins in compound grafts. The indications for the different types of graft are:
1. Intestine alone: Used in patients with intestinal failure with no evidence of terminal liver disease.

2. Liver/intestine: Indicated in patients with intestinal failure and terminal liver disease induced by prolonged parenteral nutrition.

3. Multivisceral (liver, stomach, duodenum, pancreas, small intestine): Used in patients with intestinal failure whose etiology affects the gastrointestinal tract (intestinal pseudo-obstruction, thromboembolic vascular events, and tumors). A modification can be performed with the exclusion of the liver, if the liver function of the receiver is preserved.

Current situation of Brazil in relation to intestine transplantation in children

To date, there is no record of a Brazilian child having survived intestine transplant surgery, alone or combined with the liver. Three children have undergone transplants in our country, with two passing away and the third surviving, although the graft was lost after 24 hours, as a result of arterial thrombosis. The patient remains on prolonged parenteral nutrition. Five other children were subjected to the procedure at the Jackson Memorial Hospital in Miami (USA), at an average cost of 1 million to 1.5 million dollars, all without success. Three of the chil- 
dren died as a result of the procedure and two other are awaiting a second transplant, now multivisceral due to the irreversible liver damage.

Although the current literature records that the survival of intestine transplants in children is 50 to $70 \%,{ }^{16,17}$ our study shows that the Brazilian experience is different. We found that rehabilitation of the small intestine is possible, even in the case of small remaining segments, such as minimal extensions of 10 to $15 \mathrm{~cm}$. Two of the children from the series submitted to full resection of the small intestine and part of the colon have survived for more than 5 years under a parenteral nutrition regimen, with good quality of life. Thus, the results of the Intestinal Rehabilitation Program encourage us to continue this type of treatment and stimulate the creation of the program in other pediatric care institutions.

\section{Resumo}

Tratamento da síndrome do intestino encurtado na criança: valor do Programa de Reabilitação Intestinal

A principal causa da falência intestinal aguda é a síndrome do intestino encurtado, decorrente, em geral, de ressecção de extensos segmentos de intestino delgado. Em consequência, os principais sintomas são diarreia aquosa, síndrome de má absorção, desnutrição crônica e óbito, caso o paciente não seja adequadamente tratado. Se o comprimento do intestino remanescente for superior a $30 \mathrm{~cm}$, poderá haver adaptação completa e o paciente poderá ficar livre da nutrição parenteral. O tratamento atualmente preconizado inclui a utilização de nutrição parenteral prolongada e de nutrição enteral, objetivando sempre o ganho ponderal constante, em paralelo a cirurgias que visem ao alongamento do intestino dilatado. Esse conjunto de procedimentos constitui o que se denomina Programa de Reabilitação Intestinal. Essa terapia foi utilizada em 16 crianças, em períodos que variaram de 8 meses a 7 anos e meio, com sobrevida em $75 \%$ dos casos. O último recurso utilizado em crianças com ressecção completa do intestino delgado é o transplante intestinal. Até o momento, não há registro de criança brasileira que tenha sobrevivido a esse procedimento, a despeito de sete pacientes terem sido submetidos a ele. Os resultados do Programa de Reabilitação Intestinal nos anima a continuar com esse tipo de tratamento e estimular a criação do programa em outras instituições de atendimento pediátrico.

Palavras-chave: síndrome do intestino curto, criança, falência intestinal, nutrição parenteral prolongada, reabilitação intestinal.

\section{References}

1. Olieman JF, Tibboel D, Penning C. Growth and nutritional aspects of infantile short bowel syndrome for the past 2 decades. J Pediatr Surg. 2008; 43(11):2061-9.

2. Heiji HA, Meijers-IJsselstijn H, Olieman JF, Rings EHHM, Sleeboom C, Taminiau JAJM. National Protocol Short Bowel Syndrome. National Committee Short Bowel Syndrome; 2005.

3. Tannuri U. Short bowel syndrome in children--treatment with home parenteral nutrition. Rev Assoc Med Bras. 2004; 50(3):330-7.

4. Guo M, Li Y, Li J. Effect of growth hormone, glutamine, and enteral nutrition on intestinal adaptation in patients with short bowel syndrome. Turk J Gastroenterol. 2013; 24(6):463-8.

5. Tannuri U, Tannuri AC, Maksoud JG. The second and third right posterior intercostal veins: an alternate route for central venous access with an implantable port in children. J Pediatr Surg. 2005; 40(11):e27-30.

6. Bianchi A. Intestinal lengthening: an experimental and clinical review. J R Soc Med. 1984; 77 Suppl 3:35-41.

7. Wester T, Borg H, Naji H, Stenström P, Westbacke G, Lilja HE. Serial transverse enteroplasty to facilitate enteral autonomy in selected children with short bowel syndrome. Br J Surg. 2014; 101(10):1329-33.

8. Brito IA, Mathias AL, Tannuri U, Bastos JC. Sobrevida prolongada e nutrição parenteral domiciliar em criança submetida à ressecção total do intestino delgado e ceco. J Ped (Rio de J). 1982; 52:223-8.

9. Stanger JD, Oliveira C, Blackmore Cr, Avitzur Y, Wales PW. The impact of multi-disciplinary intestinal rehabilitation programs on the outcome of pediatric patients with intestinal failure: A systematic review and metaanalysis. J Pediatr Surg. 2013; 48(5):983-92.

10. Wales PW, Kosar C, Carricato M, Silva N, Lang K, Avitzur Y. Ethanol lock therapy to reduce the incidence of catheter-related bloodstream infections in home parenteral nutrition patients with intestinal failure: preliminary experience. J Pediatr Surg. 2011; 46(5):951-6.

11. Barros F, Moreira DAR, Bueno MG, Monteriro RF, Redondo AC, Falcão MC, et al. Tratamento da doença hepática associada à nutrição parenteral prolongada com ômega 3: experiência inicial de três casos. Pediatria (São Paulo). 2011;33(3):184-90.

12. Diamond IR, Pencharz PB, Wales PW. Omega-3 lipids for intestinal failure associated liver disease. Semin Pediatr Surg. 2009; 18(4):239-45.

13. Diamond IR, Sterescu A, Pencharz PB, Kim JH, Wales PW. Changing the paradigm: omegaven for the treatment of liver failure in pediatric short bowel syndrome. J Pediatr Gastroenterol Nutr. 2009; 48(2):209-15.

14. Kaufman SS, Atkinson JB, Bianchi A, Goulet OJ, Grant D, Langnas AN, et al. Indications for pediatric intestinal transplantation: a position paper of the American Society of Transplantation. Pediatr Transplant. 2001; 5(2):80-7.

15. Okumura M, Mester $\mathrm{M}$. The coming of age of small bowel transplantation: a historical perspective. Transplant Proc. 1992; 24(3):1241-2.

16. Ganousse-Mazeron S, Lacaille F, Colomb-Jung V, Talbotec C, Ruemmele F, Sauvat F, et al. Assessment and outcome of children with intestinal failure referred for intestinal transplantation. Clin Nutr. 2015; 34(3):428-35.

17. Martinez Rivera A, Wales PW. Intestinal transplantation in children: current status. Pediatr Surg Int. 2016; 32(6):529-40. 